\title{
Asthma and indoor environment in Nepal
}

T Melsom, L Brinch, J O Hessen, M A Schei, N Kolstrup, B K Jacobsen, C Svanes, M R Pandey

\begin{abstract}
Background-The development of asthma seems to be influenced by the adoption of a Western lifestyle. A study was undertaken to assess the importance of indoor environmental factors in Nepal where the lifestyle and home environment differ from that in the West.

Methods-The home environment of 121 schoolchildren with asthma and 126 controls aged 11-17 years was studied. The homes of all participants were investigated and the children and their mothers were interviewed using a standardised questionnaire. Cases and controls were identified from an ISAAC (International Study of Asthma and Allergy in Childhood) based population study of 2330 schoolchildren in Kathmandu, Nepal.

Results-Keeping cattle inside the house during the night was related to a lower risk for having asthma (adjusted odds ratio (OR) $0.2(95 \%$ CI 0.1 to 0.5$)$ ) while there was no association between asthma and cattle kept outside. Asthma was associated with cigarette smoking by two or more family members (OR 1.9 (95\% CI 1.0 to 3.9)) and with the domestic use of smoky fuels (OR $2.2(95 \%$ CI 1.0 to 4.5$)$ ). In analyses stratified by sex, passive smoking and the use of smoky fuels were significantly associated with asthma only in boys.

Conclusions-The risk of asthma in Nepalese children was lower in subjects exposed to cattle kept inside the house and higher in subjects exposed to passive smoking and indoor use of smoky fuels. Childhood exposure to microorganisms or allergens from cattle may protect against the development of atopic disease. (Thorax 2001;56:477-481)
\end{abstract}

Keywords: asthma; domestic animals; smoky fuels; passive smoking; infection hypothesis; microbial stimulation

University of Bergen, Norway

C Svanes

Mrigendra Samjhana Medical Trust, Nepal M R Pandey

Correspondence to: Dr T Melsom, Utsikten 15 nr 1, 1604 Fredrikstad, Norway

toralfm@hotmail.com

Received 1 August 2000 Returned to authors 1 November 2000 Revised version received 1 February 2001 Accepted for publication 26 February 2001 more different cultures. A study was undertaken to assess the importance of indoor environmental factors potentially relevant for asthma in Nepal, a country where the lifestyle and home environment is different from that in the West.

Atopic diseases are reported to be more common in children exposed to animal dander than in those not exposed. ${ }^{4}$ On the other hand, findings from the European Community Respiratory Health Survey indicate that dog keeping in early childhood protects against adult atopy. ${ }^{6}$ A study of Swedish children revealed less asthma and allergic rhinitis in children who had a pet during their first year of life. ${ }^{7}$ Furthermore, recent studies of allergy in a farm environment provide evidence of less hay fever and asthma among children of farmers. ${ }^{8-10}$ In Nepal a large proportion of the population are peasants and, as in many other developing countries, there is a tradition of keeping cattle inside the house.

Maternal tobacco smoking has been identified as an important risk factor for asthma in several studies. ${ }^{112}$ A survey of smoking habits in the rural area of Kathmandu Valley showed that the prevalence of daily tobacco smoking for men and women was $85 \%$ and $62 \%$, respectively. ${ }^{13}$ Most Nepalese families use unprocessed biomass fuel such as wood, grass, and crop residues for heating and cooking. Solid fuel fired cooking and heating stoves are widely used in developing countries, and respiratory symptoms have been associated with the use of smoky fuels in $\mathrm{Nepal}^{14}$ and in other countries. ${ }^{15} 16$

In this case control study of asthma we directed special attention to a possible effect of close exposure to livestock and indoor smoke pollution. Other environmental factors of interest were pet keeping, building construction, and domestic crowding.

\section{Methods}

One hundred and thirty five cases of asthma were defined from a study in which 2330 schoolchildren aged 11-17 years were screened to study the prevalence of asthma, rhinitis, and eczema in the area of Kathmandu Valley, Nepal (M Schei, J O Hessen, M R Pandey, unpublished). This study recruited two sample groups, one within the city of Kathmandu and one from the surrounding hilly area where people still have a traditional way of life. Schools were selected randomly and data were collected in the classrooms using both a written and a video questionnaire developed by ISAAC. ${ }^{3}$ To ensure comprehension and the use of correct local language, questionnaires were first translated into Nepalese and then retranslated to English by independent persons. 
Table 1 Characteristics of 247 children with or without asthma living in the area of Katmandu Valley, Nepal

\begin{tabular}{lll}
\hline & $\begin{array}{l}\text { Cases } \\
(n=121)\end{array}$ & $\begin{array}{l}\text { Controls } \\
(n=126)\end{array}$ \\
\hline Mean age (years) & 14.1 & 14.1 \\
Male (\%) & 64 & 62 \\
Higher Indo-Aryan ethnicity (\%) & 60 & 57 \\
Traditional house construction (stone or brick and mud) (\%) & 53 & 47 \\
Rural living (\%) & 52 & 48 \\
\hline
\end{tabular}

Data on age, sex, ethnicity, and school (area of living) were collected from the ISAAC screening survey.

Ethnicity and school (area of living) were matching variables.

The 135 children defined as cases of asthma in our study answered "yes" to at least one of the following questions in each of the two different ISAAC questionnaires:

Core questionnaire: "Have you had wheezing or whistling in the chest in the last 12 months?" or "In the last 12 months have you had a dry cough at night, apart from a cough associated with a cold or chest infection?"

Video questionnaire: "Has your breathing ever been like this (moderate wheezing at rest) in the last year?" or "Have you been woken like this (nocturnal wheezing) at night in the last year?" or "Have you been woken like this (nocturnal cough) at night in the last year?" or "Has your breathing been like this (severe wheezing at rest) in the last year?"

Controls were selected randomly from children in the same study who reported never having had asthma or symptoms of asthma (as described above). Cases and controls were matched by school (reflecting area of living) and ethnicity. Ethnicity, which to some extent reflects socioeconomic status, was classified into five groups: higher Indo-Aryan, higher Newar, lower Newar, Tibeto-Burmese, and other ethnicities.

Five cases and the corresponding controls were excluded for logistical reasons, and one case was without a matching control and was therefore omitted. Of the remaining 258 schoolchildren we failed to get in touch with 11 , one because he had quit school and 10 because they were absent at the time of our fieldwork. Thus, 247 subjects were left for analyses, 121 cases of asthma and 126 controls.

The homes of all 247 participants were visited during the rainy season in July and August 1997. Two teams of field workers performed the home visits according to a standard procedure. The purpose of the visit was explained to the parents or guardians and their informed consent was obtained. No prior notice of the visit was given. An interview was performed by a Nepalese team worker using a questionnaire validated and translated by a Nepalese medical expert. Questions were asked on the issues of home environment and respiratory health. A standardised inspection of the house was then performed using a checklist with special attention to the type of cooking place.

EPI Info statistical software (version 6.0) and SAS (version 6, 4th ed) were used for data analyses. Univariate analyses were performed to test for associations between potential risk factors and the presence of asthma. Matched odds ratios computed for the comparison of paired proportions were calculated. Risk factors showing a significant association with the presence of asthma were entered into a multiple logistic regression model fitted by SAS. In this multivariate model we broke the matched design, thereby reducing the number of cases and controls excluded because of missing values. The odds ratios for major risk factors computed in the unmatched design did not differ significantly from those in the matched multivariate design computed by conditional logistic regression (data not given). Analyses stratified for smoking and sex were performed as cigarette smoke may modify the effects of other irritants and the allergen response ${ }^{17}$ and because the airways of boys and girls differ. ${ }^{18}$ Separate analyses were performed for the rural and urban populations as the exposure to environmental factors differed between these populations.

\section{Results}

Table 1 shows the characteristics of the cases and controls. Compared with the entire ISAAC study population $(n=2330)$, there were slightly more boys and more individuals from the higher Indo-Aryan ethnicity in the asthmatic group. The asthmatic group was equally divided between the urban (Kathmandu) and rural area (in Kathmandu Valley). Sixty per cent of the questionnaires were answered by the mother and $40 \%$ by the father, an elder sister, or the schoolchild itself. One hundred children lived in traditional houses (brick, stone and mud) and 147 lived in modern houses (cement). The modern houses were mostly located in Kathmandu city and the traditional ones in the rural area. The mean number of family members and elder siblings was 6.1 and 2.0 , respectively.

Neither building construction, number of family members, number of elder siblings, bed sharing, nor pet ownership was associated with having asthma (table 2). Ninety families (36\%) kept cattle (defined as buffalo, cow, horse, goat or pig) at home. Forty of these families kept their cattle inside the house at night. The animals were housed on the ground floor and often in the same room as the cooking place. From this room there was an opening in the ceiling with stairs leading to the second floor and sleeping rooms. Keeping cattle inside the house was inversely related to the risk of having asthma (tables 2 and 3). Keeping cattle in general (OR 0.9 (95\% CI 0.5 to 1.6)) or keeping cattle outside the house at night was not related to asthma (OR 1.4 (95\% CI 0.7 to 2.9$)$ ).

Keeping poultry inside the house seemed to increase the risk for asthma (table 2) and this association was upheld, although was not statistically significant, on multivariate analysis (table 3). Stratified analysis revealed that keeping poultry inside the house was a risk factor for asthma only in children who had two or more family members who smoked (unadjusted OR 3.4 (95\% CI 1.0 to 11.9 )).

For cooking, 75 families (34\%) used open fire or burning stoves without a flue (with solid fuel such as wood and grass), 43 (18\%) used gas stoves, and 106 (43\%) kerosene stoves; 63 
Table 2 Unadjusted effects of environmental factors on asthma in 119 cases and 119 matched controls in Kathmandu Valley, Nepal

\begin{tabular}{|c|c|c|c|}
\hline & No of pairs & No of discordant pairs ${ }^{\star}$ & Odds ratio ${ }^{\star *}$ \\
\hline Male sex & 119 & $30 / 25$ & $1.2(0.7$ to 2.1$)$ \\
\hline Traditional building construction & 117 & $17 / 14$ & $1.2(0.6$ to 2.6$)$ \\
\hline Traffict & 117 & $21 / 12$ & $1.8(0.8$ to 3.9$)$ \\
\hline Elder siblings & 117 & $24 / 26$ & $0.9(0.5$ to 1.7$)$ \\
\hline Bed sharing & 119 & $22 / 24$ & $0.9(0.5$ to 1.6$)$ \\
\hline Cattlet† kept inside the house at night & 117 & $7 / 19$ & $0.4(0.1$ to 0.9$)$ \\
\hline Poultry kept inside the house & 116 & $23 / 11$ & $2.1(1.0$ to 4.3$)$ \\
\hline Petsł & 117 & $22 / 23$ & $1.0(0.5$ to 1.7$)$ \\
\hline One or more smoking $₫$ family members & 116 & $22 / 21$ & $1.1(0.6$ to 2.0$)$ \\
\hline Two or more smoking $\$$ family members & 115 & $25 / 11$ & $2.3(1.1$ to 4.6$)$ \\
\hline Indoor bio smoke & 99 & $13 / 7$ & $1.9(0.7$ to 4.7$)$ \\
\hline
\end{tabular}

${ }^{\star}$ Number of pairs were case exposed and control unexposed/number of pairs were case unexposed and control exposed.

${ }^{\star \star}$ Mantel-Haenszel matched unadjusted odds ratio (95\% CI).

†Based on whether the house was located near a road with heavy traffic or not.

††Buffalo, cow, horse, goat or pig.

$\ddagger$ Pets = cat, dog, other (parrot, rabbit)

\Smoking daily inside the house.

ๆCategories based on kind of cooking place; yes=open fire or burning stove without a flue, no=gas or kerosene stove. traffic was the only significant risk factor for asthma in the urban population (matched OR 3.0 (95\% CI 1.1 to 9.2$)$ ). In the rural population asthma was strongly related to tobacco smoking (OR 3.5 (95\% CI 1.4 to 8.7$)$ ), indoor biosmoke (OR 3.3 (95\% CI 1.1 to 9.9 )), and keeping cattle inside (OR 0.2 (95\% CI 0.1 to 0.6)) (mutually adjusted odds ratios from logistic regression analysis including building construction).

\section{Discussion}

Most studies on indoor climate and asthma have been carried out in developed countries. Asthmatic patients in these countries often have knowledge about allergen removal which might confound the association between possible risk factors and asthma. It is less likely that families involved in our study actively try to avoid potential causes of asthma in their homes.

Cases and controls were selected from a questionnaire based screening survey, so the diagnosis of asthma was based on symptoms rather than the measurement of lung function or bronchial hyperreactivity. Both a written questionnaire and a video questionnaire were used according to the ISAAC protocol. A validation study in Chinese schoolchildren concluded that the ISAAC international video questionnaire provided a simple and valid tool for the diagnosis of bronchial hyperreactivity in this population. ${ }^{19}$

We found a relatively strong inverse relationship between keeping cattle inside the house and having asthma. This finding was consistent after controlling for building construction, age, sex, keeping poultry, tobacco smoke, and the use of smoky fuels. A better nutritional status in families with household animals could be a confounding factor. However, this seems unlikely as keeping cattle outside the house had no protective effect. Furthermore, keeping cattle inside the house at night represents a source of heating, so a lower use of smoky fuels for heating could bias our results. However, the proportion of children bothered by smoke coming into the sleeping room was not reduced in families who kept cattle inside the house.

Cattle kept inside represent both a reservoir of microorganisms and a source of allergensthat living in an area with observed heavy

Table 3 Adjusted odds ratios for asthma in 247 children aged 11-17 years in Kathmandu Valley, Nepal

\begin{tabular}{|c|c|c|c|c|c|}
\hline Environmental factors & $\begin{array}{l}\text { Cases } \\
(n=121)\end{array}$ & $\begin{array}{l}\text { Controls } \\
(n=126)\end{array}$ & $\begin{array}{l}\text { Crude OR } \\
\text { (95\% CI) }\end{array}$ & $\begin{array}{l}\text { Adjusted }{ }^{\star} \text { OR } \\
(95 \% \mathrm{CI})\end{array}$ & $p$ Value \\
\hline \multicolumn{6}{|c|}{ Cattlet kept inside the house } \\
\hline Yes & 14 & 26 & $0.5(0.3$ to 1.0$)$ & $0.2(0.1$ to 0.5$)$ & 0.001 \\
\hline No & 104 & 96 & 1.0 & 1.0 & \\
\hline \multicolumn{6}{|c|}{ Poultry kept inside the house } \\
\hline Yes & 29 & 19 & $1.8(1.0$ to 3.5$)$ & $2.0(0.9$ to 4.6$)$ & 0.1 \\
\hline No & 89 & 107 & 1.0 & 1.0 & \\
\hline \multicolumn{6}{|c|}{$\begin{array}{l}\text { No of family members who } \\
\text { smoke } \$\end{array}$} \\
\hline$\geqslant 2$ & 39 & 24 & $2.1(1.1$ to 3.7$)$ & $1.9(1.0$ to 3.9$)$ & 0.06 \\
\hline $0-1$ & 79 & 100 & 1.0 & 1.0 & \\
\hline \multicolumn{6}{|l|}{ Indoor biosmoke } \\
\hline Yes & 44 & 31 & $1.8(1.0$ to 3.0$)$ & $2.2(1.0$ to 4.5$)$ & 0.04 \\
\hline No & 65 & 80 & 1.0 & 1.0 & \\
\hline Missing & 12 & 15 & & & \\
\hline
\end{tabular}

${ }^{\star}$ Mutually adjusted for cattle kept inside the house, tobacco smoke, indoor biosmoke and poultry.

+Buffalo, cow, horse, goat or pig.

\$Smoking daily inside the house.

TCategories based on kind of cooking place; yes=open fire or burning stove without a flue, no=gas or kerosene stove. 
directly through ectoparasites living on the animals, excrement, and dander and indirectly through mites in fodder. ${ }^{2021}$ The cattle were kept on the ground floor, usually in the same room or next door to the kitchen/cooking place. Most houses had openings in the ceiling or the walls that separated the rooms. Family members could be exposed to microorganisms and allergens both through inhalation and ingestion. There is little migration in the area and we assume that the families had kept their animals in a similar way for several years. Thus, early life exposure could be as important as exposure at the time of the investigation.

The inverse association between keeping cattle inside the house and asthma could be explained by the "infection hypothesis". ${ }^{22}$ This theory suggests that reduced microbial exposure during the first years of life, particularly exposure to infections with intracellular pathogens, may be disadvantageous in terms of sensitisation to allergy. The development of resistance or sensitivity to environmental antigens depends to a large extent on the nature of the immunological memory which is generated during infancy and early childhood. ${ }^{23} \mathrm{~T}$ cell selection that favours the production of $\mathrm{T}$ helper 2 (Th2) cells increases the likelihood of atopic disease. ${ }^{24}$ Many intracellular pathogens generate a predominantly Th1 cell cytokine profile that is thought to downregulate the Th2 cell mediated immune mechanism. Animal experiments have shown that $\mathrm{Th} 2$ responses to an inhaled allergen in highly responsive young rats could be suppressed by exposure to infections and microbial adjuvants concomitantly with the allergen. ${ }^{17}$ The protective effect of childhood exposure to animals seen in this study, in studies of early exposure to pets, ${ }^{67}$ and in studies in the farm environment ${ }^{8-10}$ might result from a contribution by the animals to the microbial environment which promotes the development of a non-allergic immunity. The hypothesis of microbial stimulation may thus provide a unifying explanation for the inverse association between allergy and family $\operatorname{size}^{6225}$ and the protective effect of childhood exposure to animals. Alternatively, the protective effect of early exposure to cattle could be related to the development of tolerance.

Keeping cattle inside the house, in particular, could provide an exposure to endoparasites in cattle excrement and to ectoparasites living on the cattle. ${ }^{21}$ It has been suggested that a high frequency of parasitism during early childhood may be associated with a lower prevalence of asthma ${ }^{26}{ }^{27}$ and the role of parasitic infections in the development of asthma has been the subject of several studies. ${ }^{28}$ Improved sanitary conditions in developed countries have reduced exposure to parasites and may be a contributing factor to the increasing prevalence of allergic disease.

Although not statistically significant, keeping poultry seemed to increase the risk for asthma in our study. Exposure to indoor mite and cat allergens has been associated with increased sensitisation and asthma. ${ }^{29}{ }^{30}$ Likewise, poultry allergens may be more potent in inducing asthmatic symptoms than allergens from other domestic animals such as dogs and cattle. Exposure to poultry has been associated with wheezing and bronchial hyperreactivity in other studies, ${ }^{31}{ }^{32}$ and high concentrations of mites are found in dust from poultry in Nepal and elsewhere. ${ }^{33} 34$

Smoking inside the house by at least two family members was an important risk factor for asthma in our study. Unfortunately, we did not specify maternal or paternal smoking. We assume, however, that one smoker (prevalent in the city) means that the father smoked and that "two or more family members" (prevalent in the rural areas) in most cases implied that both father and mother smoked. In the rural area of Kathmandu Valley Pandey et al found a high prevalence of smoking in both men $(85 \%)$ and women $(62 \%)$. Few of the female smokers were concerned about the harmful effects of smoking on their own health $(18.6 \%)$ or on the health of others $(1.3 \%){ }^{12}$ Most of the female smokers in our study probably smoked during pregnancy. As no harmful effect was found in households with only one smoker, we speculate that maternal smoking in pregnancy could be of importance, as well as postnatal passive smoking. Increased asthma risk related to both these exposures has been observed in previous studies in the Western world. ${ }^{11}{ }^{12}$

We found no effect of passive smoking in the urban area. This could be related to the limited exposure as in most families there was only one smoker. Furthermore, passive smoking seemed to be more harmful in homes with smoky fuels (OR smoking 4.1 (95\% CI 1.4 to 12.5$)$ ), which applied mostly in the rural area, than in those without $\left(\mathrm{OR}_{\text {smoking }} 1.1\right.$ (95\% CI 0.4 to 2.8$)$ ).

The use of smoky fuels was associated with asthma in our study. Domestic biomass fuel combustion has been associated with reduced lung function or asthma in some, ${ }^{15}{ }^{16}$ but not all, $^{35}$ s6 studies. Carbon monoxide, nitrogen dioxide, and suspended particulate matter are important air pollutants produced by combustion of biofuels and very high concentrations of total suspended particles have been measured in kitchens with open fires or non-vented stoves in Nepal and in other countries. ${ }^{37}{ }^{38}$ Women in Nepal spend a considerable time near the fireplace. Direct exposure of children to smoky fuels, as well as maternal exposure during pregnancy, could explain our findings.

The harmful effects of passive smoking and of smoky fuels were of greatest significance in boys. This could be related to the fact that boys have relatively narrower airways than girls during childhood ${ }^{18}$ and, furthermore, boys tend to have more airway infections and more asthma than girls during this age period. ${ }^{18}$ The literature on passive smoking gives conflicting results with regard to sex differences in susceptibility, ${ }^{39}$ with some studies showing a greater effect of passive smoking in boys. A possible sex difference in the susceptibility to damage by airway irritants needs to be addressed in larger studies.

In conclusion, we found that keeping cattle inside the house during the night was related to less asthma in Nepalese children. There was no effect when cattle were kept outside the house, 
which suggests a particular effect of close exposure to livestock. Our findings support the concept that the microbiological environment during early childhood influences the prevalence of asthma. Stimulation of the Th1 pathway early in life by microbes from cattle could be a possible mechanism; induction of tolerance by early exposure to allergens from cattle is an alternative explanation. The fact that our findings from Nepal agree with studies of the effects of pets and a farm environment on the prevalence of asthma in the West suggests that the underlying mechanisms are of universal importance in the physiology of asthma and underlines the need for further research in the area.

Our study further suggests that passive smoking and exposure to smoky fuels increases the risk of asthma in childhood. This is also in agreement with reports of asthma and passive smoking in the West and points to a general role of airway irritants in promoting asthma. As well as direct exposure, maternal tobacco smoking and exposure to smoky fuels in pregnancy may also have been important in this study.

The authors acknowledge the Mrigendra Samihana Medical Trust and especially Gauri Saud, Shiva Ram Thapa, Shiva Raj Trust and especially Gauri Saud, Shiva Ram Thapa, Shiva Raj Ghimire, Mrs B Shresta, and Mr P R Pathak for great efforts
during the period of the fieldwork in Nepal. They also wish to during the period of the fieldwork in Nepal. They also wish to thank Dr Roald Bolle, Department of Pediatrics, University of
Tromsø, Norway and Kjell Andersson, Department of EnvironTroms $ø$, Norway and Kjell Andersson, Department of Environ-
mental Health, Hospital of Ørebro for their helpful contribumental Health, Hospital of Ørebro for their helpful contributions. Financial support was received from the Centre for Envi-
ronment and Development (SEMUT) at the University of ronment and Developm
Tromsø and from Astra.

1 Bjørksten B. Risk factors in early childhood for the development of atopic diseases. Allergy 1994;49:400-7.

2 Yemaneberhan H, Bekele Z, Venn A, et al. Prevalence of wheeze and asthma and relation to atopy in urban and rural Ethiopia. Lancet 1997;350:85-90

3 The International Study of Asthma and Allergies in Childhood (ISAAC) Steering Committee. Worldwide variation in prevalence of symptoms of asthma, allergic rhinoconjunctivitis, and atopic eczema: ISAAC. Lancet 1998;351: 1225-32.

4 Gupta S, Bidani RK, Jhamb S, et al. Role of animal danders as inhalent allergens in bronchial asthma in India. 7 Asthma 1996;33:339-48.

5 Abdulrazzaq YM, Bener A, DeBuse P. Pet ownership in the UAE: its effect on allergy and respiratory symptoms. $\mathcal{F}$ Asthma 1995;32:117-24.

Asthma 1995;32:117-24.
6 Svanes C, Jarvis D, Chinn S, et al. Childhood environment and adult atopy: results from the European Community and adult atopy: results from the European Community Respiratory

7 Hesselmar B, Åberg N, Åberg B, et al. Does early exposure to cat or dog protect against later allergy development? Clin Exp Allergy 1999;29:611-7.

8 Braun-Fahrländer C, Gassner M, Grize L, et al. Prevalence of hay fever and allergic sensitisation in farmer's children and their peers living in the same rural community. Clin Exp Allergy 1999;29:28-34.

9 Riedler J, Eder W, Oberfeld G, et al. Austrian children living on a farm have less hay fever, asthma and allergic sensitization. Clin Exp Allergy 2000;30:194-200.

10 Von Ehrenstein OS, Von Mutius E, Illi S, et al. Reduced risk of hay fever and asthma among children of farmers. Clin Exp Allergy 2000;30:187-93.

11 Strachan DP, Cook DG. Parental smoking and childhood asthma: longitudinal and case-control studies. Thorax 1998;53:204-12.
12 Søyseth V, Kongerud J, Boe J. Postnatal maternal smoking increases the prevalence of asthma but not of bronchial hyperresponsiveness or atopy in their children. Chest 1995; 07:389-94

13 Pandey MR, Neupane RP, Akshaya G. Epidemiological study of tobacco smoking behaviouramong adults in a rural community of the hill region of Nepal with special reference to attitude and beliefs. Int F Epidemiol 1988;17(3).

14 Pandey MR. Domestic smoke pollution and chronic bronchitis in a rural community of the hill region of Nepal. Thorax 1984;39:337-9.

15 Mohamed N, Ng'ang'a N, Odhiambo J, et al. Home environment and asthma in Kenyan schoolchildren: a casecontrol study. Thorax 1995;50:74-8.

16 Guneser S, Atici A, Alparslan N, et al. Effects of indoor environmental factors on respiratory systems of children. $\mathcal{F}$ Trop Pediatr 1994;40:114-6.

17 Sedwick JD, Holt PG. Suppression of IgE responses in inbred rats by repeated respiratory tract exposure to antigen: responder phenotype influences isotype specificity of induced tolerance. Eur F Immunol 1984;14:893-7.

18 Becklake MR, Kauffmann F. Gender differences in airway behaviour over the human life span. Thorax 1999;54:1119-

19 Lai-CK, Chan JK, Chan A, et al. Comparison of the ISAAC video questionnaire (AVQ3.0) with the ISAAC written questionnaire for estimating asthma associated with questionnaire for estimating asthma associated with

20 Rautianinen M, Virtanen T, Ruoppi P, et al. Humoral responses to bovine dust in dairy farmers with allergic rhinitis. Acta Otolaryngol 1997;529(Suppl):169-72.

21 Terho EO, Husman K, Vohlonen I, et al. Allergy to storage mites or cow dander as a cause of rhinitis among Finnish dairy farmers. Allergy 1985;40:23-6.

22 Strachan D. Hay fever, hygiene and household size. BMF 1989;289:1259-60.

23 Holt PG. Infections and the development of allergy. Toxicol Lett 1996;86:205-10.

24 Holt PG. A potential vaccine strategy for asthma and allied atopic diseases during early childhood, Lancet 1994;344: $456-8$

25 Bråback L, Breborowicz A, Jugle K, et al. Risk factors for respiratory symptoms and atopic sensitisation in the Baltic area. Arch Dis Child 1995;72:487-93.

26 Godfrey RC. Asthma and IgE levels in rural and urban communities in the Gambia. Clin Allergy 1975;5:201-7.

27 Warrell DA, Fawcett IW, Harrison BDW, et al. Bronchial asthma in the Nigerian savanna region: a clinical and laboratory study of 196 patients with a review of the literature on asthma in the tropics. $Q \mathcal{F}$ Med 1975;44:325-47.

28 Lynch RL, Goldblatt J, Souef PNL. Parasite infections and the risk of asthma and atopy. Thorax 1999;54:659-60.

29 Platts-Mills TAE, Sporik RB, Chapman MD. The role of indoor allergens in asthma. Allergy 1995;50:5-12.

30 Gelber LE, Seltzer LH, Bouzoukis JK, et al. Sensitization and exposure to indoor allergens as risk factors for asthma among patients presenting to hospital. Am Rev Respir Dis 993; 147:573-8.

31 Zuskin E, Mustajbegovic J, Kern J, et al. Respiratory function in poultry workers. Lijec Vjesn 1995;117:121-5.

32 Tudor A, Racoveanu C, Gheorghiu M, et al. Study of respiratory and immunologic changes in the workers of a poultry farm. Med Interne 1985;23:129-34.

33 Schei M, Hessen JO, Bolle R, et al. A study of mites in indoor environment and prevalence of asthmatic symptoms in rural Nepal. Proceedings of the International Conference on Indoor Air Quality and Climate 1996;4:657-62.

$34 \mathrm{Mehl}$ R. Occurrence of mites in Norway and the rest of Scandinavia. Allergy 1998;53:28-35.

35 Noorhassim I, Rampal KG, Hashim JH. The relationship between prevalence of asthma and environmental factors in rural households. Med 7 Malaysia 1995;50:263-7.

36 Azizi BH, Zulkifli HI, Kasim S. Indoor air pollution and asthma in hospitalized children in a tropical environment. $\mathcal{F}$ Asthma 1995;32:413-8.

37 Yadav B, Hessen JO, Schei M, et al. Effect on indoor air pollution level from introducing improved stoves in rural Nepal. Proceedings of the International Conference on Indoor Air Quality and Climate 1996;4:113-7.

38 McCracken JP, Albalak R, Boy E, et al. Improved stove or inter-fuel substitution for decreasing indoor air pollution from cooking with biomass fuels in highland Guatemala. Proceedings of the 8th International Conference on Indoor Air Quality and Climate 1999;3:118-29.

39 Cook DG, Strachan DP. Parental smoking, bronchial reactivity and peak flow variability in children. Thorax 1998:53:295-301. 